\title{
Canadian doctors say it is inappropriate for them to prescribe marijuana
}

Some ambiguity resulted from the editing of this news story written by Charlotte Santry (BMJ 2012;345:e8623, doi:10.1136/ bmj.e8623). Health Canada is a government department and does not prescribe medical marijuana, as stated in the story. The federal government has proposed transferring the overarching responsibility for providing access to marijuana from Health Canada to individual doctors, who would write documents similar to prescriptions. Also, a Health Canada spokeswoman explained to the $B M J$ that the growth in the number of registered users of the scheme would diminish as a result of the changes, because some users would grow plants illegally or choose different treatment options. The impact assessment for the proposals predicted that the price of legally bought medicinal marijuana would rise from the current \$C5 (£3;€3.8;\$US5) a gram to $\$ 8.80$ a gram, as it would no longer be subsidised.

Cite this as: BMJ 2013;346:f183

๑ B BMJ Publishing Group Ltd 2013 